\title{
EL VIDEOCLIP COMO MERCANARRATIVA
}

\author{
Ana María SEDEÑo VALDELLóS \\ Universidad de Málaga \\ valdellos@uma.es
}

Resumen: El artículo reflexiona sobre la narratividad del videoclip musical según el modelo de análisis semiótico de los textos del grupo Entrevernes, llegando a la conclusión de que éste prefiere otros recursos discursivos como el mecanismo seductor.

Abstract: The article reflects on the narrativity in music video according to the model of semiotic analysis of texts from the Entrevernes group, arriving at conclusion that this one prefers other discursive resources like the mechanism of seduction.

Palabras clave: Vídeo musical. Narratividad. Semiótica en el videoclip.

Key words: Music video. Narrativity. Semiotic in music video. 


\section{LA MERCANARRATIVA}

La mercanarrativa supone el conjunto de modalidades narrativas que fundamentan su naturaleza en su función de ser vehículos de objetivos o finalidades publicitarias o comerciales.

La publicidad, en diferentes fórmulas como la audiovisual, la cartelería, la fotografía publicitaria..., así como el videoclip musical, pueden ubicarse en esta megacategoría formada por el criterio de la funcionalidad publicitaria u otros fines mercantiles.

Naturalmente, con quien más comparte este rasgo narrativo es con la publicidad audiovisual, con la que tiene otros rasgos en común, definidores de la especificidad del discurso audiovisual publicitario (Moreno, 2003: 97):

- Discurso aplicado y extraordinariamente elíptico.

- Predominio de la seducción sobre la información.

- Finalidad persuasiva.

- Sometimiento a la audiencia.

- Subordinación consciente a las modas.

- Duración breve.

- Permanencia efímera.

- Medios humanos y materiales múltiples.

- Autoría compartida y subsumida a favor del anunciante.

- Estilemas de marca por encima de los autoriales.

- Constricciones múltiples.

La mayoría de estos atributos los recibe como efectos de un condicionante productivo: su finalidad persuasiva al servicio de unos intereses de marca, para el que se ponen en marcha toda una serie de recursos humanos y técnicos complejos de alto coste económico.

\section{LA NECESIDAD DE MECANISMOS SOCIALES DE PRODUCCIÓN DE DESEO}

La mayoría de la gente ignora que el mundo es un producto humano, que se puede construir, manipular y crear teniendo los medios necesarios, es 
decir, que no es natural ni inamovible. Quienes sostienen esto aprovechan esta ignorancia para manipular a su antojo la realidad y la percepción que tienen de ella los demás, con el fin de obtener un beneficio sustancial.

El formato audiovisual del videoclip es producido y emitido con unos fines, iguales que los de la publicidad convencional, para lo que se sirve del mismo mecanismo, el de seducción, que tiene efectos y consecuencias sobre la sociedad y, especialmente, en un segmento de la población determinado, la juventud.

De esta forma, la implantación del capitalismo trajo consigo, por un lado, la existencia de excedentes productivos, a los que se debía dar salida mediante el consumo, y, por otro, unos mayores niveles de renta para la mayoría de la población. La subsistencia estaba cubierta y fue posible dar el salto generalizado hacia el consumo de productos innecesarios o de lujo.

El consumo está basado en una necesidad anterior a la compra del producto. Los nuevos excedentes, resultado de una revolución tecnológica sin aparente freno, eran sobre todo productos nuevos, en su mayoría de lujo: productos de los que, en principio, no había necesidad. Por ello, el sistema industrial capitalista tuvo que configurar un mecanismo de creación de necesidades. Ésta es la que muchos autores han llamado industria de producción de deseo, de la que es baluarte esencial la publicidad y, por ende, el videoclip. Éste no es más que una fórmula singular para vender un tipo de producto concreto, la música (un tipo especial de música: el pop y el rock), a través de la imagen (física) o de la personalidad (atractiva) de sus autores.

Estos mecanismos de incitación social de deseo son una parte fundamental del funcionamiento del sistema de producción-consumo capitalista, en igual medida que las industrias que fabrican los bienes y mercancías a los que va destinado ese deseo.

Para potenciar estas necesidades y para incitar el deseo, es imprescindible influir sobre valores, normas, creencias, hábitos de vida y consumo, psicológicos y sociales, y, en definitiva, sobre la percepción de la realidad y el mundo físico y mental.

El videoclip y la publicidad prometen una movilidad social de tipo ideal: se asocia un producto a un determinado grupo de referencia normalmente superior o supuestamente deseable (y a sus valores, normas, comportamientos y también beneficios sociales); su compra es el camino o la condición indispensable para engrosar las filas de ese grupo de referencia. Se transforma el producto en símbolo de estatus social. 
Pero ¿cómo hace esto el videoclip y la publicidad audiovisual? ¿Cuál es el mecanismo a través del que se vehiculan estos valores?

\section{EL MECANISMO DE SEDUCCIÓN}

Es en el mecanismo seductor donde se encuentra la principal similitud entre publicidad y videoclip musical, base de la modalidad mercanarrativa que ejemplifican. Publicidad audiovisual y videoclip tienen en común el constituir dos mecanismos de seducción, dirigidos a persuadir al espectador/consumidor, para que realice un acto de compra. Pero ¿es ése el único aspecto que podemos destacar de su existencia?

Decididamente no. Para comprender la idea hay que señalar primero el hecho siguiente: el videoclip (y un poco menos el espot publicitario) es para la mayoría del público joven urbano el género o espacio que más le gusta de la televisión. Los vídeos musicales se consumen, al margen de que se produzca una acción posterior de compra de la música que publicitan.

Una prueba de ello es que existen, en todo el mundo, cadenas de televisión, dedicadas a la exclusiva emisión de estos formatos audiovisuales, y que existen programas monográficos donde son emitidos y comentados, mientras se informa sobre la actualidad musical.

Si el videoclip y espot son capaces de convertirse en objeto de consumo ellos mismos, es que realizan operaciones seductoras. Es necesario por tanto realizar una diferenciación entre operación retórica y seducción.

Según González Requena, la retórica consiste en la construcción de un discurso informativo y persuasivo que tiene como referente el objeto publicitado. Este discurso es performativo (presupone una acción posterior) y transitivo (porque diferencia el anunciador del enunciatario y se refiere a una tercera persona él, el producto referente).

La seducción en cambio es intransitiva; la relación de consumo es inmediata, sin necesidad de un acto posterior, y se agota en la interpelación permanente al destinatario, en la relación enunciador/enunciatario, que se materializa sublimemente en el videoclip mediante la mirada del (de los) músico(s) al espectador. Lo comenta González Requena (1992: 59):

Una mirada, una distancia, un cuerpo que se exhibe afirmado como imagen que fascina. He aquí entonces, los elementos necesarios para una situación 
de seducción. Pues lo que pretende el cuerpo que reexhibe es seducir, es decir, atraer - apropiarse - de la mirada deseante del otro.

En el discurso retórico, la imagen del objeto es signo: el objeto es sólo un referente, no está presente en el discurso. Por el contrario, como opinan González Requena y Ortiz de Zárate (1995: 20), la seducción «alucina el objeto de deseo, se impone como presencia».

En el discurso retórico, el enunciador despliega una argumentación ante el enunciatario para que se convenza del beneficio o bondad de un objeto (que es un referente): es decir, se introduce un tercero, un él (aparte del yo —enunciador-y del tú —enunciatario-). Sin embargo:

Si se habla de enunciación seductora, es preciso añadir en seguida que se trata de una enunciación que no responde en lo esencial a una función informativa (transmitir información) ni retórica (argumentar, convencer), sino fática, que acentúa hasta el paroxismo el contacto comunicativo entre el «yo»y el «tú» no como figuras diferenciales, sino, bien por el contrario, como figuras propiamente fusionales.

(...) la estructuración dual-fática del espot, el predominio absoluto del par «yo-tú», excluye todo "él» y al hacerlo dificulta la articulación del discurso en el plano narrativo (González Requena y Ortiz de Zárate, 1995: 23).

Ésta es la razón por la que la inmensa mayoría de los videoclips son descriptivos. Si ese tercer término, que hace posible la narración, nos es arrebatado, y no puede captarse nuestra atención por esta vía, ¿qué hace seductor a un videoclip; qué nos ofrece?

Pues una imagen fascinante que nos atrapa desde el principio, que exhibe sus formas, sus múltiples caras (a lo largo del desarrollo del clip) y que finaliza presentándose como un todo coherente, único e imperecedero que invita a ser revisionado.

Lo que Requena dice del espot es perfectamente aplicable al videoclip: él presenta un objeto visualmente absoluto (la relación entre el grupo y la canción es ese objeto) con la ayuda de una puesta en escena hiperrealista y una fotografía extremadamente definida, de mucha calidad, que consigue gran densidad cromática (gracias a elevadas inversiones). Sin embargo, el objeto sufre un proceso de irrealización, se vuelve inverosímil ya que no se inserta en un contexto real, sino imaginario. Todo videoclip construye una puesta en escena y una situación que el espectador sabe irreal e increíble. 
El objeto publicitado por todo clip es superficialmente la música de un determinado artista o grupo. Sin embargo, es realmente la unión de esa música con esos actores y con su imagen. Un clip intenta naturalizar o volver inevitable la relación entre un cantante o grupo (y la imagen o look de éste o éstos) y su música; intenta vender música mostrándonosla unida a imágenes convencionalmente articuladas.

Esta convencionalidad es en todo momento escondida, provocando puntos de sincronización entre la imagen y la música (corte de plano a ritmo de música; transiciones...) y haciendo que el cantante y demás miembros del grupo aparezcan en imagen cantando el tema sincrónicamente.

La seducción que despliega un videoclip es muy palpable, directa y explícita (como en un spot) y se materializa, sobre todo, a través de códigos connotativos visuales y de una especial relación entre éstos y el componente musical.

\section{LA NARRATIVIDAD EN EL VIDEOCLIP}

Según algunas corrientes semióticas (Entrevernes, 1982), el análisis del componente narrativo es el estudio de la sucesión de estados y cambios que caracterizan a sujeto y objeto en el discurso y los papeles que asumen en las actuaciones de cambio. Se tiene en cuenta que existe narratividad con la existencia de un programa narrativo. El programa narrativo es la sucesión de estados y cambios que se encadenan en la relación de un sujeto y un objeto (siendo éstos no personajes o cosas, sino papeles, nociones que definen posiciones correlativas); es la serie de pasos o cambios de un estado (relación de un sujeto y un objeto) a otro.

La secuencia narrativa está compuesta por cuatro fases lógicamente articuladas. Una o varias secuencias narrativas formarán el programa narrativo (no es obligatoria la existencia de las cuatro fases para la constitución de un programa narrativo):

- Fase de influjo: es la fase en la que otro sujeto (calificante) emprende una actividad para que el sujeto principal ejecute un programa dado. Es una acción cognitiva de persuasión llamada influjo. En ella un sujeto intenta influir sobre otro sujeto. Es la fase del hacer-hacer, la fase inicial que pone en marcha un programa narrativo, es decir, se establece un sujeto para las realizaciones que se han de efectuar o se 
presentan realizaciones (objetos) y se persuade a alguien de que han de ser ejecutadas.

- Fase de capacidad: la adquisición de un objeto por el sujeto presupone que este último es capaz de efectuar dicha realización. En dicha fase, el sujeto debe adquirir las condiciones necesarias para realizar el cambio en la relación sujeto-objeto, así como las capacidades para llegar a conseguir el objeto.

- Fase de realización: es la principal en la consecución de un programa narrativo, en la que el sujeto realiza un cambio en la relación con el objeto.

En la fase inicial el objeto está en un estado de unión o de desunión con el sujeto. En la final esta relación se habrá invertido: cuando se pasa de un estado de desunión a otro de unión (el sujeto adquiere o consigue el objeto) estamos ante una realización de unión; cuando se pasa de un estado de unión a otro de desunión (el sujeto ha perdido o está privado del objeto) se produce una realización de desunión.

- Fase de valoración: en ella se produce una acción de evaluación o actividad interpretativa del estado final de la realización (reconocer que el cambio ha tenido lugar y evaluar la actuación del sujeto).

Junto a todo programa narrativo siempre hay un antiprograma narrativo, con un antisujeto $u$ oponente que tiene como objeto un elemento opuesto a aquél.

La narración como elemento o mecanismo para provocar la atención e interés del espectador no se utiliza en demasía en el videoclip: simplemente no parece ser el mecanismo más adecuado para ello. El videoclip prefiere la descripción para sus objetivos.

La narración, ya de por sí minoritaria, se prefiere en la fase de realización, y en algunos clips puede encontrarse también en la de capacidad, lo que no es extraño si se atiende a la materialidad icónica del vídeo. Las fases cognitivas del programa narrativo (influjo y valoración) son minoritarias o nulas.

\section{TIPOLOGÍA DEL VIDEOCLIP}

Desde este punto de vista pueden clasificarse tres tipos de videoclips musicales, atendiendo a su mayor o menor interés por el desarrollo de programas narrativos: 
- Narrativo: en los que pueden vislumbrarse un programa narrativo. Algunos poseen desarrollos muy convencionales: a veces el cantante es el protagonista de la historia, mientras canta o baila. Esto ya ocurría en un precedente claro del clip: la película musical Qué noche la de aquel día (A Hard Days Night, Richard Lester, 1964) de The Beatles. Estos microrrelatos suelen poseer las características propias de un film: marcadas elipsis, flujo continuo y transición transparente entre imágenes; raccord; fundido a negro como elemento de puntuación espacio-temporal o separador de bloques. Pero todo ello sin olvidar la deuda del videoclip con las vanguardias artísticas: junto a estos elementos se produce la ruptura de los tradicionales parámetros espaciotemporales, para intentar negar la convencionalidad de la narración.

- Descriptivo: no albergan ningún programa narrativo en sus imágenes, sino que basan su discurso visual en unos códigos de realización y de reiteración musicovisual, similares al del espot televisivo y más útlil para sus objetivos seductores.

- Descriptivo-narrativo: es una mezcla de los dos anteriores. En ellos suele existir un nivel diegético, de la historia, y otro nivel en el que simplemente se ve al cantante o grupo actuando en un escenario más o menos extravagante, o en cualquier otro sitio. Éste es el tipo de videoclip que suele elegirse cuando se desea representar algún tipo de argumento temporal con un desarrollo narrativo muy reducido y constreñido.

Esta clasificación puede completarse con la siguiente, mucho más habitual en la terminología y tradición crítica —no únicamente semiótica— sobre el videoclip musical:

- Dramático o narrativo: aquellos en los que se presenta una secuencia de eventos donde se narra una historia bajo la estructura dramática clásica, en los cuales la relación de la imagen con la música puede ser lineal (la imagen repite punto por punto la letra de la canción), de adaptación (se estructura una trama paralela, a partir de una canción) y de superposición (se cuenta una historia que puede funcionar independientemente de la canción, aún cuando en conjunto provoque un significado cerrado).

- Musical o performance: la banda icónica únicamente es testigo del hecho musical, ya sea en concierto o estudio, o bien consiste en una ilustración estética de la melodía, con lo que únicamente adquiere un 
carácter escenográfico sin hacer referencia a nada más. La meta es crear cierto sentido de una experiencia en concierto. Vídeos orientados al performance indican al espectador que la grabación de la música es el elemento más significativo.

- Conceptual: se apoyan sobre forma poética, sobre todo en la metáfora. No cuentan una historia de manera lineal, lo que hacen es crear cierto ambiente o estética de tipo abstracto o surrealista. Puede ser una secuencia de imágenes con un concepto en común en colores o formas que, unidos por la música, forman un cuadro semiótico que expresa el sentir de la música, no precisamente la letra de la canción. Tanto los vídeos performances como los conceptuales son una especie de subclasificación de los descriptivos.

- Mixto: es una combinación de alguna de las clasificaciones anteriores.

\section{POR UNA DEFINICIÓN DEL VIDEOCLIP MUSICAL}

De esta forma, puede caracterizarse al videoclip como un formato-producto en la medida en que consiste en una elaboración intencional de un conjunto de entidades empresariales, económicas y sociales para cubrir unos objetivos lucrativos, con el consiguiente peso e influencia socio-político-económicos. Es decir, nos encontramos ante un objeto o mercancía fabricado por un determinado tipo de industrias, denominadas en terminología socioeconómica industrias culturales o industrias de la cultura. Veamos una definición:

Recreación visual, con música de fondo, de una canción que tiene como objetivo la promoción y venta de los discos que editan las casas discográficas y es producido por éstas o por los agentes de los artistas (Levín, 2002).

El término industrias culturales se refiere a la producción cultural que está organizada como industria, en cuanto a producción en serie, masiva, con diferenciación de funciones y división especializada del trabajo. «Existe industria cultural cuando la representación de alguna obra se transmite o reproduce mediante técnicas industriales» (Flichy, 1982: 37). La aparición de las industrias culturales hizo posible el concepto de cultura de masas y de medios de comunicación masivos:

Productoras y distribuidoras de mercancías con contenidos simbólicos, concebidas para un trabajo creativo, organizadas por un capital que se valoriza 
y destinadas finalmente a los mercados de consumo, con una función de reproducción ideológica y social (Zallo, 1988: 26).

En el caso del videoclip, las industrias implicadas son la discográfica, la de producción audiovisual y la televisiva, que conforman el producto en todas sus fases.

La industria discográfica encarga realizar un videoclip a una agencia o productora audiovisual como herramienta promocional, pieza clave inserta en una campaña de lanzamiento de un tema musical de un determinado cantante o grupo.

Este formato será retransmitido por televisión, dirigido a un target potencial que determina su inserción en una cadena, dependiente de cuestiones como el precio de emisión.

De este modo, las fases de producción, realización y de distribución se ven colmadas como en cualquier producto industrial, y, a su vez, como toda mercancía, el videoclip sufre procesos de estandarización de sus formas y de socialización de sus contenidos. El objetivo de estos procesos es la venta (de tracks/canciones y/o álbumes), gracias a la creación de bienes con alto contenido simbólico que satisfacen necesidades culturales y que, por tanto, adquieren un valor de uso.

Pero, además, el videoclip es un género audiovisual. El concepto de género podría definirse como un modo diferenciado de gestionar las materias expresivas de la imagen y el sonido, con una intencionalidad global coherente, a través de un conjunto de recursos estables y uniformes de naturaleza temática, enunciativa y retórica. En el videoclip, esta estrategia de regularidad general es sustituida por un conjunto de irregularidades de todo tipo que parte de todos los géneros y los pone en crisis (los transforma y los cita), de forma que sería más procedente hablar de macrogénero (son posibles todas las mezclas caprichosas entre géneros), intergénero (especie de género multimedia, donde la música, la imagen y el texto forman una especie de conducto multimedia). El videoclips se desarrolla sobre la mezcla y combinación de recursos formales y retóricos de procedencia indistinta.

Si se define la organización formal o modo de funcionamiento de un texto audiovisual como la «trama de operaciones formales con diversos grados de heterogeneidad, en relación a recursos regulares (materiales y formales) y posibles características de su consumo» (Leguizamón, 2002), la operación cardinal que conforma el modo videoclip resulta de la capacidad del tema musi- 
cal para condicionar las modificaciones de todos los parámetros de la imagen en su composición (interna), en su planificación y en su sucesión.

Obsérvense las características más sobresalientes que definen al videoclip actual, resumen de todas las cuestiones que se han apuntado:

a) Tiene fines publicitarios: su objetivo principal y relativamente manifiesto es la venta de un disco, una canción o tema determinado y, más sutilmente, la imagen y personalidad de un grupo o de un solista. Aunque este tipo de formato nació íntimamente ligado con la publicidad, los grandes presupuestos que mueve permiten múltiples posibilidades de creación, así como la contratación de los mejores equipos técnicos. Ello ha hecho posible la consecución de otro tipo de logros: a través de él se crea ideología y modos de comportamiento, estereotipos sociales y referencias culturales y vitales.

b) Es una combinación o mezcla de música, imagen (imagen móvil y notaciones gráficas) y lenguaje verbal (y excepcionalmente otras materias audiovisuales: ruido, silencio y diálogos). La idea de la que parte un videoclip resulta del intento de asociar unas imágenes a una música siempre preexistente, anterior. Éste constituye, sin duda, el rasgo particular que diferencia al vídeo musical de las demás producciones audiovisuales, aunque eso no signifique que no sea imitado sistemáticamente por otras modalidades o formatos audiovisuales.

c) Constituye un discurso específico, particularizado, que tiene su andamiaje en la especial relación que establecen imagen y sonido (música) en relación a unos fines publicitarios ya expuestos.

\section{CONCLUSIONES}

El videoclip no emplea habitualmente el mecanismo narrativo, optando por el mecanismo seductor, más útil para sus fines, pues centra el interés sobre el objeto anunciado, no haciendo referencia a ningún tercer elemento, lo que supondría una distracción.

Ese objeto absoluto es visualizado mediante una puesta en escena hiperrealista ayudada por una fotografía de mucha calidad, pero que es sometida a un proceso de irrealización mediante el uso de códigos visuales como el cambio de plano, la angulación de la cámara, la iluminación... es decir, 
desplegándose como imagen en proceso infinito de cambio, de formación, y todo ello al ritmo de la música.

\section{REFERENCIAS BIBLIOGRÁFICAS}

FLICHY, P. (1982). Las multinacionales del audiovisual. Barcelona: Gustavo Gili.

GonzÁlez Requena, J. (1992). El discurso televisivo: espectáculo de la posmodernidad. Madrid: Cátedra.

GonzÁlez Requena, J. y Ortiz de ZÁRATe, A. (1995). El espot publicitario: las metamorfosis del deseo. Madrid: Cátedra.

Grupo EnTREVERnes (1982). Análisis semiótico de los textos: Introducción, Teoría, Práctica. Madrid: Ediciones Cristiandad.

Moreno, I. (2003). Narrativa audiovisual publicitaria. Barcelona: Paidós Ibérica.

Leguizamón, J. A. (2002). El videoclip como formato o género h. En la página electrónica http://www.fortunecity.co/victorian/bacon/1244/Le guiz.html.

Levin, E. (2002). Ruido visual. En la página electrónica http://www.iztapa lapa.uam.mx./iztapala.www/topodrilo/38/td38_09.html.

ZALlo, R. (1988). Economía de la comunicación y la cultura. Madrid: Akal. 